\title{
Prehospital identification of trauma patients with early acute coagulopathy and massive bleeding: results of a prospective non-interventional clinical trial evaluating the Trauma Induced Coagulopathy Clinical Score (TICCS)
}

\author{
Martin L Tonglet ${ }^{1 *}$, Jean Marc Minon ${ }^{2}$, Laurence Seidel ${ }^{3}$, Jean Louis Poplavsky ${ }^{4}$ and Michel Vergnion ${ }^{5}$
}

\begin{abstract}
Introduction: Identifying patients who need damage control resuscitation (DCR) early after trauma is pivotal for adequate management of their critical condition. Several trauma-scoring systems have been developed to identify such patients, but most of them are not simple enough to be used in prehospital settings in the early post-traumatic phase. The Trauma Induced Coagulopathy Clinical Score (TICCS) is an easy-to-measure and strictly clinical trauma score developed to meet this medical need.

Methods: TICCS is a 3-item clinical score (range: 0 to 18) based on the assessment of general severity, blood pressure and extent of body injury and calculated by paramedics on-site for patients with severe trauma. This non-interventional prospective study was designed to assess the ability of TICCS to discern patients who need DCR. These patients were patients with early acute coagulopathy of trauma (EACT), haemorrhagic shock, massive transfusion and surgical or endovascular haemostasis during hospitalization. Diagnosis of EACT was assessed by both thromboelastometry and conventional coagulation tests.

Results: During an 18-month period, 89 severe trauma patients admitted to the general emergency unit at our hospital were enrolled in the study, but 7 were excluded for protocol violations. Of the 82 remaining patients, 8 needed DCR and 74 did not. With receiver operating characteristic curve analysis, TICCS proved to be a powerful discriminant test (area under the curve $=0.98 ; 95 \% \mathrm{Cl}: 0.92$ to 1.0). A cutoff of 10 on the TICCS scale provided the best balance between sensitivity (100\%; 95\% Cl: 53.9 to 100) and specificity (95.9\%; 95\% Cl: 88.2 to 99.2). The positive predictive value was $72.7 \%$, and the negative predictive value was $100.0 \%$.

Conclusion: TICCS can be easily and rapidly measured by paramedics at the trauma site. In this study of blunt trauma patients, TICCS was able to discriminate between patients with and without need for DCR. TICCS on-site evaluation should allow initiation of optimal care immediately upon hospital admission of patients with severe trauma in need of DCR. However, a larger multicentre prospective study is needed for in-depth validation of TICCS.

Trial registration: Clinicaltrials.gov ID: NCT02132208 (registered 6 May 2014)
\end{abstract}

\footnotetext{
* Correspondence: tongletm@yahoo.com

${ }^{1}$ Emergency Medicine, Trauma and Bleeding Care, CHR de la Citadelle,

boulevard du 12eme de ligne, 1, 4000 Lige, Belgium

Full list of author information is available at the end of the article
} 


\section{Introduction}

Uncontrolled exsanguinating haemorrhage is the leading cause of death within the first 48 hours after severe trauma [1-3]. Almost $25 \%$ of major trauma patients present with a trauma-induced coagulopathy characterized by an initial haemorrhagic phenotype (early acute coagulopathy of trauma (EACT)) and a potential late procoagulant phenotype [4-6]. Previously thought to be the consequence of the old lethal triad concept (hypothermia, dilution, coagulopathy), EACT is actually a far more complex phenomenon that occurs with a haemorrhagic phenotype in the early phase after trauma [4].

Initiating damage control resuscitation (DCR) as early as possible after severe trauma in patients with EACT is pivotal for patient survival [7]. This specific and aggressive therapeutic strategy and its components have been widely studied and debated [8-13], but one aspect remains essential for the patients outcome: The treatment has to be initiated as early as possible to be efficient [8]. DCR combines damage control surgery, permissive hypotension and early aggressive haemostatic resuscitation. However, it also implies surgical and transfusion resources available in trauma centres 24 hours per day, 7 days per week. For economic reasons, these resources cannot be offered immediately upon admission to emergency units of general hospitals, because a minimal delay is required for organization.

Identification of trauma patients who need DCR is a real challenge. The presence of EACT is strongly associated with the need for DCR. The results of recent studies suggest that standard coagulation tests such as the international normalized ratio (INR) or the activated partial thromboplastin time help in the detection of EACT, but these measures are time-consuming and probably lack relevance to guide the clinician in transfusion management. Thromboelastometric (TEM) assays may be better in identifying EACT and can rapidly bring clinically useful information $[8,14,15]$. However, the clinical predictive value of TEM has not been clearly established in this setting, and TEM probably underestimates the potential presence of early occult hyperfibrinolysis. All potential biological coagulation analyses, however, require that the patient has been admitted to the hospital, and they are time-consuming.

Several trauma scoring systems have been developed for stratification of the patients risk for the need for massive transfusion (MT) or the existence of EACT [16-24]. To be predictive, these scores generally include weighted and sophisticated systems, making them difficult to be used in routine practice. All of them, except the coagulopathy of severe trauma (COAST) score, require not only clinical data but also laboratory investigations or medical ultrasonic examinations [19], delaying their use at least a few minutes after hospital admission.
Thus, they do not allow prehospital identification of patients who need DCR.

In Belgium, in the absence of trauma centres, trauma patients are referred to general hospitals. Thus, in our hospital (CHR de la Citadelle, Lige, Belgium), about 50 severe trauma patients are referred to our emergency unit each year, diluted among more than 65,000 nontrauma cases. This dilution prohibits maintaining the necessary organisation for immediate initiation of DCR and therefore preventing trauma patients with EACT to be optimally managed. In order to offer DCR to severe trauma patients with EACT at hospital admission, we developed the Trauma Induced Coagulopathy Clinical Score (TICCS), aiming to flag trauma patients who need DCR at the site where the traumatic injury has taken place so that the hospital can take the necessary organisational steps before the patients arrival.

In contrast to currently available trauma scoring systems, TICCS was developed as an easy-to-use, strictly clinical score that can be calculated quickly by paramedics at the trauma site. It does not require any laboratory tests, X-rays or ultrasound information, as opposed to other trauma scores (for example, Trauma Associated Severe Haemorrhage (TASH), assessment of blood consumption (ABC), Prince of Wales Hospital (PWH) score, Schreiber score, Larsen score or Vandromme score). The three clinical components of the score were selected on the basis of practicability and known relationships to trauma severity and risk for active bleeding, namely: general severity of the trauma, blood pressure and extent of tissue injuries. In contrast to the COAST score, the prehospital body

Table 1 Definition and scoring system of the Trauma Induced Coagulopathy Clinical Score (TICCS)

\begin{tabular}{ll}
\hline Criteria & $\begin{array}{l}\text { Number of points } \\
\text { attributed }\end{array}$ \\
\hline General severity & 2 \\
Critical (to be admitted in resuscitation room) & 0 \\
Non critical (regular ED room) & 5 \\
Blood pressure & 0 \\
SBP below 90 mmHg at least once & \\
SBP always above 90 mmHg & 1 \\
Extent of significant injuries & 1 \\
Head and neck & 1 \\
Left upper extremity & 1 \\
Right upper extremity & 1 \\
Left lower extremity & 2 \\
Right lower extremity & 2 \\
Torso & 2 \\
Abdomen & 0 to 18 \\
Pelvis & \\
Total possible score &
\end{tabular}

${ }^{a} E D$, Emergency department; SBP, Systolic blood pressure. 
Table 2 Characteristics of the study population $(N=82)^{a}$

\begin{tabular}{|c|c|c|c|c|c|}
\hline Variable & Category & $N$ & $n(\%)$ & Median (IQR) & Range \\
\hline \multirow[t]{3}{*}{ Sex } & & 82 & & & \\
\hline & $\mathrm{F}$ & & $18(22.0)$ & & \\
\hline & M & & $64(78.1)$ & & \\
\hline Age (yr) & & 82 & & 34.5 (23.0 to 45.0 ) & 14.0 to 82.0 \\
\hline ISS & & 82 & & 13.0 (9.0 to 22.0$)$ & 4.0 to 66.0 \\
\hline \multirow[t]{3}{*}{ EXTEM } & & 50 & & & \\
\hline & Hypocoagulability & & $8(16.0)$ & & \\
\hline & Normal & & $42(84.0)$ & & \\
\hline \multirow[t]{3}{*}{ FIBTEM } & & 50 & & & \\
\hline & Hypocoagulability & & $13(26.0)$ & & \\
\hline & Normal & & $37(74.0)$ & & \\
\hline INR at admission & & 81 & & $1.1(1.0$ to 1.1$)$ & 1.0 to 2.9 \\
\hline INR after $3 \mathrm{hr}$ & & 69 & & 1.1 (1.1 to 1.2$)$ & 1.0 to 2.1 \\
\hline Fibrinogen at admission $(\mathrm{g} / \mathrm{L})$ & & 81 & & 2.7 (2.1 to 3.2$)$ & 0.4 to 6.4 \\
\hline Fibrinogen after 3 hr (g/L) & & 68 & & 3.0 (1.8 to 3.7$)$ & 0.7 to 8.5 \\
\hline $\mathrm{Hb}$ at admission (g/L) & & 81 & & 13.9 (12.7 to 15.0$)$ & 6.7 to 16.7 \\
\hline Admission base excess & & 82 & & $-1.0(-4.0$ to 0.0$)$ & -16.0 to 3.0 \\
\hline \multirow[t]{3}{*}{ Haemorrhagic shock } & & 82 & & & \\
\hline & No & & $71(86.6)$ & & \\
\hline & Yes & & $11(13.4)$ & & \\
\hline \multirow[t]{3}{*}{ Emergent surgical haemostasis } & & 82 & & & \\
\hline & No & & $71(86.6)$ & & \\
\hline & Yes & & $11(13.4)$ & & \\
\hline SBP at admission (mmHg) & & 82 & & 130 (120 to 140$)$ & 60.0 to 200.0 \\
\hline Glasgow Coma Scale & & 82 & & 11.0 (3.0 to 15.0$)$ & 3.0 to 15.0 \\
\hline 24-hr survival & & & 75 (91.5) & & \\
\hline 30-day survival & & & $72(87.8)$ & & \\
\hline
\end{tabular}

${ }^{a}$ EXTEM, Extrinsic thromboelastometry; FIBTEM, Fibrinogen thromboelastometry; Hb, Haemoglobin; INR, International normalized ratio; ISS, Injury Severity Score; SBP, Systolic blood pressure.

temperature was not considered as a relevant predictor. Further, there was no incorporation of difficult aspects, such as diagnosis of pelvic dislocation or abdominal bleeding. The TICCS system attributes a score totalling between 0 and 18 points as described hereafter: (1) General severity of the trauma: 2 points are attributed if the patient is judged in critical condition and to be oriented to the resuscitation room (based on the general severity of the trauma: kinetics considerations, airway and breathing examinations, Glasgow Coma Scale) and 0 otherwise (that is, to be oriented to a regular emergency department room). (2) Blood pressure: 5 points are attributed if the prehospital systolic blood pressure is below $90 \mathrm{mmHg}$ at least once and 0 if it stayed continuously above $90 \mathrm{mmHg}$. (3) Extent of tissue injuries: 11 points are attributed for the extent of body injury, depending on the presence of a significant injury, as follows: 1 point for the head and neck region, 1

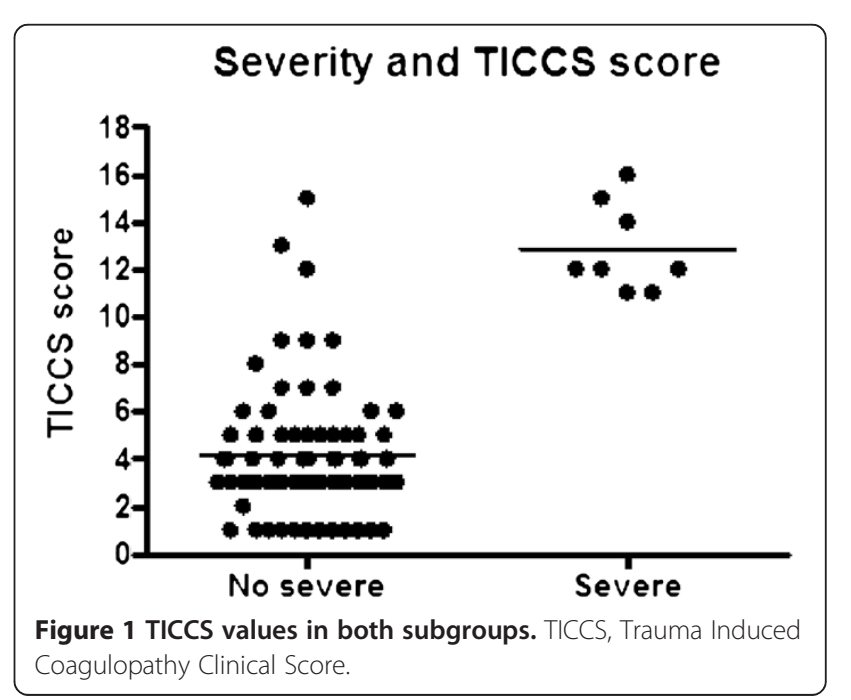


point for each four extremities, 2 points for the torso region, 2 points for the abdominal region and 2 points for the pelvic region (Table 1). Paramedics and prehospital doctors were trained how to calculate TICCS.

The present study was conducted to evaluate the efficacy of TICCS to discriminate major trauma patients requiring DCR from those who do not.

\section{Material and methods}

This prospective, single-centre, non-interventional, noncontrolled, open clinical study was submitted to and approved by the Ethics Committee of our hospital (CHR de la Citadelle, Lige, Belgium). Considering the noninterventional nature of the study and the impossibility of obtaining the patients informed consent before their enrolment in the study, the study was authorized by the concerned institutional ethics committee without informed consent. The study started in January 2012 and ended in June 2013.

For all patients, the TICCS was calculated and recorded before any measurement of hospital severity parameters. Complementary to TICCS, the Injury Severity

Table 3 Patients characteristics by Trauma Induced Coagulopathy Clinical Score groups ${ }^{\text {a }}$

\begin{tabular}{|c|c|c|c|c|c|c|}
\hline \multirow[b]{2}{*}{ Variables } & \multirow[b]{2}{*}{ Category } & \multicolumn{2}{|c|}{ TICCS $<10$} & \multicolumn{2}{|c|}{ TICCS $\geq 10$} & \multirow[b]{2}{*}{$P$-values } \\
\hline & & $N$ & Median (IQR) $n(\%)$ & $N$ & Median (IQR) or $n(\%)$ & \\
\hline \multirow[t]{3}{*}{ Sex } & & 71 & & 11 & & 0.44 \\
\hline & $\mathrm{F}$ & & $17(23.9)$ & & $1(9.1)$ & \\
\hline & M & & $54(76.1)$ & & $10(90.9)$ & \\
\hline Age (yr) & & 71 & $34.0(23.0$ to 45.0$)$ & 11 & 35.0 (18.0 to 43.0$)$ & 0.94 \\
\hline \multirow[t]{3}{*}{ EXTEM } & & 43 & & 7 & & $<0.0001$ \\
\hline & Hypocoagulability & & $1(2.3)$ & & $7(100.0)$ & \\
\hline & Normal & & $42(97.7)$ & & $0(0.0)$ & \\
\hline \multirow[t]{3}{*}{ FIBTEM } & & 43 & & 7 & & $<0.0001$ \\
\hline & Hypocoagulability & & $6(14.0)$ & & $7(100.0)$ & \\
\hline & Normal & & $37(86.0)$ & & $0(0.0)$ & \\
\hline INR at admission & & 71 & $1.0(1.0$ to 1.1$)$ & 10 & $1.3(1.1$ to 1.4$)$ & 0.0048 \\
\hline INR after $3 \mathrm{hr}$ & & 60 & 1.1 (1.1 to 1.2$)$ & 9 & $1.4(1.3$ to 1.5$)$ & 0.0002 \\
\hline Fibrinogen at admission $(\mathrm{g} / \mathrm{L})$ & & 71 & $2.8(2.2$ to 3.3$)$ & 10 & 1.7 (1.3 to 2.0$)$ & 0.0041 \\
\hline Fibrinogen after 3 hr (g/L) & & 59 & $3.2(2.3$ to 3.8$)$ & 9 & 1.5 (1.3 to 1.5$)$ & $<0.0001$ \\
\hline $\mathrm{Hb}$ at admission (g/L) & & 71 & $13.9(13.1$ to 15.1$)$ & 10 & 12.4 (9.4 to 14.0$)$ & 0.026 \\
\hline \multirow[t]{3}{*}{ Haemorrhagic shock } & & 71 & & 11 & & $<0.0001$ \\
\hline & No & & 70 (98.6) & & $1(9.1)$ & \\
\hline & Yes & & $1(1.4)$ & & $10(90.9)$ & \\
\hline \multirow[t]{3}{*}{ Emergent surgical haemostasis } & & 71 & & 11 & & $<0.0001$ \\
\hline & No & & $67(94.4)$ & & $4(36.4)$ & \\
\hline & Yes & & $4(5.6)$ & & $7(63.6)$ & \\
\hline RBCs transfused day $1(\mathrm{U})$ & & 71 & $0.0(0.0$ to 1.0$)$ & 11 & $6.0(3.0$ to 12.0$)$ & $<0.0001$ \\
\hline FFP transfused day $1(U)$ & & 71 & $0.0(0.0$ to 0.0$)$ & 11 & $4.0(2.0$ to 8.0$)$ & $<0.0001$ \\
\hline Platelets transfused & & 71 & & 11 & & 0.0002 \\
\hline \multirow[t]{2}{*}{ day 1} & No & & $71(100.0)$ & & $7(63.6)$ & \\
\hline & Yes & & $0(0.0)$ & & $4(36.4)$ & \\
\hline \multirow[t]{3}{*}{ 24-hr survival } & & 71 & & 11 & & $<0.0001$ \\
\hline & No & & $1(1.4)$ & & $6(54.6)$ & \\
\hline & Yes & & $70(98.6)$ & & $5(45.4)$ & \\
\hline \multirow[t]{3}{*}{ 30-day survival } & & 71 & & 11 & & 0.0002 \\
\hline & No & & $4(5.6)$ & & $6(54.6)$ & \\
\hline & Yes & & $67(94.4)$ & & $5(45.4)$ & \\
\hline
\end{tabular}


Score, ABC and TASH scores were also measured in the emergency unit $[19,20]$. The presence of EACT was assessed by thromboelastometry using ROTEM (Tem Innovations, Munich, Germany) at the latest 30 minutes after patient admission and by standard coagulation tests (INR, fibrinogen). Coagulopathy was defined as the presence of a significant abnormality (more than 20\%) for at least one of the following parameters in ROTEM: clotting time, clot formation time, maximum clot firmness (MCF) and maximum lysis for extrinsic thromboelastometry or MCF for fibrinogen thromboelastometry or as INR $>1.3$ at admission and/or after 3 hours, or fibrinogen $<1.5 \mathrm{~g} / \mathrm{L}$ at admission and/or 3 hours later. Coagulation tests were carried out by laboratory technicians not aware of the TICCS value.

Haemorrhagic shock was assessed by the attending physician at the time of hospital admission on the basis of persistent hypotension due to proven active bleeding. The transfusion of more than $4 \mathrm{RBC}$ units and more than 3 fresh frozen plasma (FFP) units within the first hour of care was defined as a MT. The global need for transfusion within the first 24 hours was also recorded. Surgical or endovascular haemostatic procedures were recorded throughout hospitalization. Patients who were dying because of a confirmed haemorrhagic shock at the early phase of care in the resuscitation room before being able to benefit from surgery were classified as needing emergent surgical haemostasis and MT. The study patients were categorized in two groups. Severe patients (in need of DCR) were those satisfying all three clinical criteria (diagnosis of haemorrhagic shock associated with MT, use of surgical or endovascular haemostatic procedure) and the laboratory criterion (EACT). By contrast, nonsevere patients (not in need of DCR) were defined as patients who did not fulfil at least one of the four criteria stated above.

Quantitative variables were summarized as median and interquartile range (IQR) as well as range, and frequency tables were used for categorical findings. Group comparisons were done by applying the Kruskal-Wallis test for continuous variables and the $x^{2}$ test (or Fisher $\mathrm{s}$ exact test) for categorical variables. The cutoff value for TICCS was obtained by ROC curve analysis based on the severity of the patients condition. Each trauma score was characterized by its sensitivity, specificity, positive and negative predictive values (PPV and NPV) and area under the ROC curve (AUC) with 95\% confidence intervals $(95 \% \mathrm{CI})$. The results were considered significant at the $5 \%$ critical level $(P<0.05)$. Calculations were performed with the SAS version 9.3 for Windows statistical software package (SAS Institute, Cary, NC, USA).

\section{Results}

Between January 2012 and June 2013, about 100,000 patients were admitted to the emergency unit of our hospital. Among them, 89 (0.09\%) had severe trauma and were enrolled in the study. Seven patients were excluded from the analysis, however, because of protocol violations or complete absence of data. Thus, the statistical analysis was based on 82 study patients. Their characteristics are described in Table 2.

Among the 82 patients, 74 were classified as nonsevere and 8 as severe (in need of DCR). The median (IQR) TICCS was 3 [3-5] for nonsevere patients and 12 [12-15] for severe patients (Figure 1). The two groups differed significantly $(P=0.0011)$. ROC curve analysis showed that TICCS was able to discriminate between severe and nonsevere patients with an AUC of 0.98 (95\% CI: 0.92 to 1.0$)$. Further, a TICCS cutoff value of 10 yielded the best trade-off between true positives and false positives. Table 3 displays the characteristics of the study patients according to TICCS $<10$ and TICCS $\geq 10$. The corresponding sensitivity and specificity of TICCS were 100\% (95\% CI: 53.9 to 100) and 95.9\% (95\% CI: 88.2 to 99.2), respectively, and the PPV and NPV were equal to $72.7 \%$ (95\% CI: 43.3 to 68.6$)$ and $100 \%$ (95\% CI: 94.7 to 100), respectively. These figures are superior to those obtained for the other scores (see Table 4 and Figure 2). The three false-positive patients (TICCS $\geq 10$ but nonsevere) had EACT but did not meet all three clinical criteria (Table 5).

\section{Discussion}

Early identification of trauma patients in need of DCR is essential to provide adequate treatment upon hospital admission and to have a major impact on their outcomes [25]. By contrast, initiation of DCR in patients who do not require this aggressive therapy may negatively affect their survival [26]. The on-site flagging of severe trauma patients on the basis of TICCS has potential to be beneficial for general emergency units that are not expected to be ready for this rare situation 24 hours per day, 7 days per week. It should also be useful for highperforming trauma centres to identify such patients and transfer them immediately to the resuscitation room

\section{Table 4 Comparison of sensitivity, specificity, positive and negative predictive value and area under the receiver operating characteristic curve of the various trauma scores measured during the study ${ }^{a}$}

\begin{tabular}{lrrrrr}
\hline Score cutoff & SE (\%) & SP (\%) & PPV (\%) & NPV (\%) & AUC \\
\hline TICCS $\geq 10$ & 100.0 & 95.9 & 72.7 & 100.0 & 0.98 \\
ISS $\geq 25$ & 86.5 & 100.0 & 44.4 & 100.0 & 0.93 \\
ABC $\geq 2$ & 100.0 & 94.6 & 66.7 & 100.0 & 0.97 \\
TASH $\geq 16$ & 100.0 & 62.5 & 100.0 & 96.1 & 0.81 \\
\hline
\end{tabular}

${ }^{a} A B C$, Assessment of blood consumption; AUC, Area under the receiver operating characteristic curve; ISS, Injury Severity Score; NPV, Negative predictive value; PPV, Positive predictive value; SE, Sensitivity; SP, Specificity; TASH, Trauma Associated Severe Haemorrhage; TICCS, Trauma Induced Coagulopathy Clinical Score. 


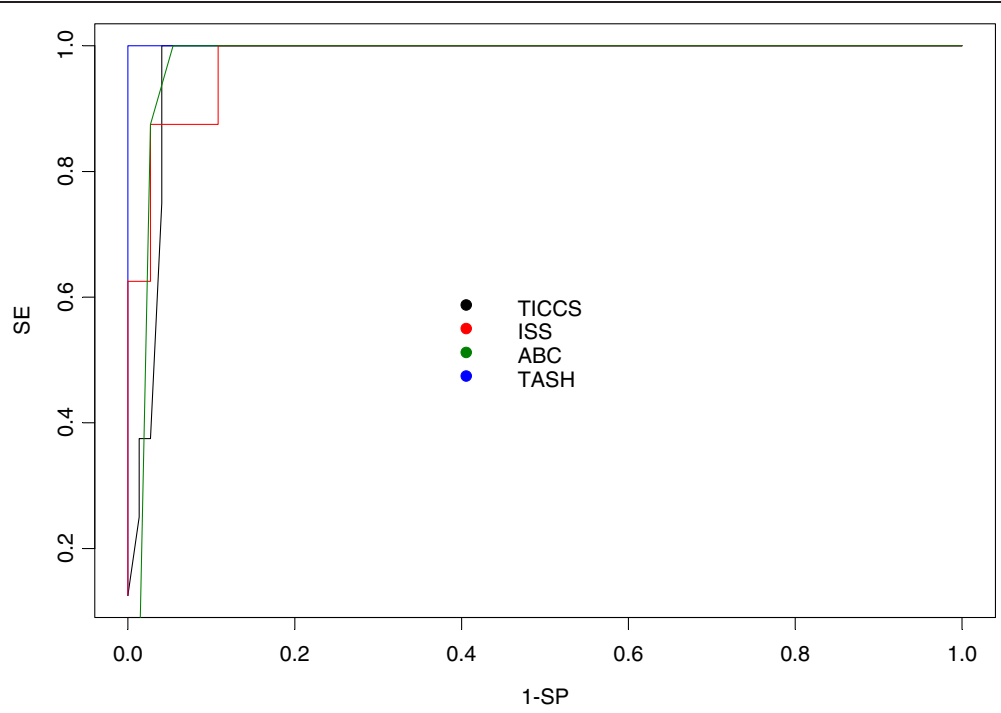

Figure 2 Area under the receiver operating characteristic curve of the measured scores. ABC, Assessment of blood consumption; ISS, Injury Severity Score; SE, Sensitivity; SP, Specificity; TASH, Trauma Associated Severe Haemorrhage; TICCS, Trauma Induced Coagulopathy Clinical Score.

upon admission. This would in turn avoid the use of colloids or lead to initiation of prehospital administration of blood products and/or haemostatic agents and MT protocols. Finally, TICCS could be useful for triaging patients in collective trauma situations. It should be noted that, as our trauma population consisted essentially of blunt trauma patients, at present the use of TICCS should be restricted to such patients.

Although based on a limited sample size, the study evidenced TICCS as a potential candidate for on-site identification of severe trauma patients in need of DCR. Larger multicentre studies are needed to confirm these preliminary results.

\section{Conclusions}

The results of the present clinical study confirm that TICCS, an easy and quick severe trauma scoring system measured on site by paramedics, has the ability to identify patients in need of DCR. Early prehospital flagging of those patients should allow general emergency units to mobilize the specific resources requested to offer high-quality DCR for the limited number of patients

Table 5 Characteristics of the three nonsevere patients with Trauma Induced Coagulopathy Clinical Scores $\geq 10^{a}$

\begin{tabular}{lllll}
\hline $\begin{array}{l}\text { Patient } \\
\text { no. }\end{array}$ & $\begin{array}{l}\text { Haemorrhagic } \\
\text { shock }\end{array}$ & $\begin{array}{l}\text { Emergent surgical } \\
\text { haemostasis }\end{array}$ & $\begin{array}{l}\text { Massive } \\
\text { transfusions }\end{array}$ & EACT \\
\hline 1 & No & No & No & Yes \\
2 & Yes & Yes & No & Yes \\
3 & Yes & No & No & Yes \\
\hline
\end{tabular}

${ }^{a}$ EACT, Early acute coagulopathy of trauma; TICCS, Trauma Induced Coagulopathy Clinical Score. who need it (impact on cost-effectiveness of patients support) and to shorten the time between injury and DCR initiation (impact on patients survival). The MT protocol in place at our hospital [27] can be activated in due time, allowing thawing the necessary FFP units and preparing the packed $\mathrm{RBC}$ and platelet units before patient admission. Surgeons and interventional radiologists will also be ready for interventions for the patients. The TICCS differs from the other scores, such as $A B C$, TASH, Vandromme or PWH, by being purely clinical and easy to compute by paramedics at the site of injury. Our study results also show that the diagnostic ability of TICCS was superior to ABC and TASH. Besides its interest for general emergency units, the TICCS could also prove to be a useful tool for high-quality trauma centres and trauma systems in terms of prehospital triage and management, especially in the setting of prehospital bleeding management and transfusion of blood products and use of haemostatic agents or crystalloids and colloids.

\section{Key messages}

- Prehospital identification of patients with severe trauma who need DCR is a prerequisite for correct early management of such high-risk patients.

- Most existing trauma scoring systems cannot be calculated on site before a patients admission to the emergency unit.

- TICCS can potentially fulfil this medical need and could have a significant impact on patient mortality.

- TICCS is an easily and rapidly computed score that can be used by paramedics at the trauma site. 
- For blunt trauma patients, TICCS demonstrates a clear ability to discriminate patients with vs without a need for DCR.

- Further validation of TICCS is needed to confirm the presently reported results, such as by means of larger, multicentre, prospective studies.

\begin{abstract}
Abbreviations
ABC: Assessment of blood consumption; AUC: Area under the receiver operating characteristic curve; COAST: Coagulopathy of severe trauma; DCR: Damage control resuscitation; EACT: Early acute coagulopathy of trauma; EXTEM: Extrinsic thromboelastometry; FFP: Fresh frozen plasma; FIBTEM: Fibrinogen thromboelastometry; INR: International normalized ratio; ISS: Injury Severity Score; MCF: Maximum clot firmness; MT: Massive transfusion; NPV: Negative predictive value; PPV: Positive predictive value; PWH: Prince of Wales Hospital; RBC: Red blood cell; ROC: Receiver operating characteristic; TASH: Trauma Associated Severe Haemorrhage; TICCS: Trauma Induced Coagulopathy Clinical Score.
\end{abstract}

\section{Competing interests}

The authors declare that they have no competing interests. Octapharma Benelux SA financially contributed to the study (buying of reagents for ROTEM), but it has no financial interest linked to the data published.

\section{Authors contributions}

MT developed the TICCS instrument and was involved in the conceptualization, literature review, data extraction, data analysis, writing of the manuscript and final editing. JMM was involved in the conceptualization, data extraction and revision of the manuscript. LS was involved in data analysis and interpretation and revision of the manuscript. MV was involved in the conceptualization, data extraction and revision of the manuscript. JLP contributed to the conception and design of the study, to the study protocol and to the redaction of the manuscript. All authors read and approved the final manuscript.

\section{Authors information}

MT works as an emergency medicine resident in the emergency department of the CHR de la Citadelle, Lige, Belgium. JMM is head of the laboratory and blood transfusion departments at the CHR de la Citadelle. LS is working as a biostatistician at the University Hospital of Lige. JLP is chief executive officer of European Drug Development Consulting, a consulting company that specializes in clinical research. MV is the head of the emergency department of the CHR de la Citadelle.

\section{Acknowledgements}

We thank the staff of the emergency, laboratory and blood transfusion departments of the CHR de la Citadelle, Lige, Belgium, for their enthusiastic participation in this study. We are grateful to Professor Emeritus Adelin Albert for statistical advice and counselling, to Octapharma Benelux SA for financial support in purchasing reagents and thromboelastometric assays, to Francois Pitance for revising the manuscript, to Pierre Lovinfosse for his help in data extraction and to Laura Deben for her support throughout the study.

\section{Author details}

${ }^{1}$ Emergency Medicine, Trauma and Bleeding Care, CHR de la Citadelle, boulevard du 12eme de ligne, 1, 4000 Lige, Belgium. ${ }^{2}$ Laboratory and Blood Transfusion Departments, CHR de la Citadelle, boulevard du 12eme de ligne, 1, 4000 Lige, Belgium. ${ }^{3} \mathrm{CHU}$ du Sart Tilman, departement des biostatistiques, domaine du Sart Tilam, B35, 4000 Lige, Belgium. ${ }^{4}$ European Drug Development Consulting, rue du Tambour, 4, 4540 Amay, Belgium. ${ }^{5}$ Emergency Department, CHR de la Citadelle, boulevard du 12eme de ligne, 1, 4000 Lige, Belgium.

Received: 24 April 2014 Accepted: 6 November 2014

Published online: 26 November 2014

\section{References}

1. Sauaia A, Moore FA, Moore EE, Moser KS, Brennan R, Read RA, Pons PT Epidemiology of traumatic deaths: a reassessment. J Trauma 1995, 38:185 193.
2. Acosta J, Yang JC, Winchell RJ, Simons RK, Fortlage D, Hollingsworth-Fridlund P, Hoyt DB: Lethal injuries and time to death in a level I trauma center. J Am Coll Surg 1998, 186:528 533.

3. Kauvar DS, Lefering R, Wade CE: Impact of hemorrhage on trauma outcome: an overview of epidemiology, clinical presentations and therapeutic considerations. J Trauma 2006, 60(6 Suppl):S3 S11.

4. Brohi K, Singh J, Heron M, Coats T: Acute traumatic coagulopathy. J Trauma 2003, 54:1127 1130.

5. Macleod J, Lynn M, McKenney M, Cohn SM, Murtha M: Early coagulopathy predicts mortality in trauma. J Trauma 2003, 55:39 44

6. Maegele M, Lefering R, Yucel N, Tjardes T, Rixen D, Paffrath T, Simanski C, Neugebauer E, Bouillon B, the AG Polytrauma of the German Trauma Society (DGU): Early coagulopathy in multiple injury: an analysis from the German Trauma Registry on 8724 patients. Injury 2007, 38:298 304.

7. Beekey AC: Damage control resuscitation: a sensible approach to the exsanguinating surgical patient. Crit Care Med 2008, 36(7 Suppl):S267 S274.

8. Spahn DR, Bouillon B, Cerny V, Coats TJ, Duranteau J, Fernndez-Mondjar E, Filipescu D, Hunt BJ, Komadina R, Nardi G, Neugebauer E, Ozier Y, Riddez $L$, Schultz A, Vincent JL, Rossaint R: Management of bleeding and coagulopathy following major trauma: an updated European guideline. Crit Care 2013, 17:R76.

9. Johansson PI, Oliveri R, Ostrowski SR: Hemostatic resuscitation with plasma and platelets in trauma: a meta-analysis. J Emerg Trauma Shock 2012, 5:120 125.

10. Duchesne JC, Hunt JP, Wahl G, Marr AB, Wang YZ, Weintraub SE, Wright MJ, McSwain NE Jr: Review of current blood transfusions strategies in a mature level I trauma center: Were we wrong for the last 60 years? J Trauma 2008, 65:272 278.

11. Holcomb JB, Wade CE, Michalek JE, Chisholm GB, Zarzabal LA, Schreiber MA, Gonzalez EA, Pomper GJ, Perkins JG, Spinella PC, Williams KL, Park MS: Increased plasma and platelet to red blood cell ratios improves outcome in 466 massively transfused civilian trauma patients. Ann Surg 2008, 248:447 458.

12. Duchesne JC, Kimonis K, Marr AB, Rennie KV, Wahl G, Wells JE, Islam TM, Meade P, Stuke L, Barbeau JM, Hunt JP, Baker CC, McSwain NE Jr: Damage control resuscitation in combination with damage control laparotomy: a survival advantage. J Trauma 2010, 69:46 52.

13. CRASH-2 Trial Collaborators, Shakur H, Roberts I, Bautista R, Caballero J, Coats T, Dewan Y, El-Sayed H, Gogishaishvili T, Gupta S, Herrera J, Hunt B, Iribhogbe P, Izurieta M, Khamis H, Komolafe E, Marrero MA, Meja-Mantilla J, Miranda J, Morales C, Olaomi O, Olldashi F, Perel P, Peto R, Ramana PV, Ravi RR, Yutthakasemsunt S: Effects of tranexamic acid on death, vascular occlusive events and blood transfusion in trauma patients with significant haemorrhage (CRASH-2): a randomized, placebo-controlled trial. Lancet 2010, 376:23 32

14. Ganter MT, Hofer CK: Coagulation monitoring: current techniques and clinical use of viscoelastic point-of-care coagulation devices. Anesth Analg 2008, 106:1366 1375.

15. Holcomb JB, Minei KM, Scerbo ML, Radwan ZA, Wade CE, Kozar RA, Gill BS, Albarado R, McNutt MK, Khan S, Adams PR, McCarthy JJ, Cotton BA: Admission rapid thromboelastography can replace conventional coagulation tests in the emergency department: experience with 1974 consecutive trauma patients. Ann Surg 2012, 256:476 486.

16. Baker JB, Korn CS, Robinson K, Chan L, Henderson SO: Type and crossmatch of trauma patient. J Trauma 2001, 50:878 881.

17. McLaughlin DF, Niles SE, Salinas J, Perkins JG, Cox ED, Wade CE, Holcomb JB: A predictive model for massive transfusion in combat casualty patient. J Trauma 2008, 64(2 Suppl):S57 S63.

18. Mitra B, Cameron P, Mori A, Maini A, Fitzgerald M, Paul E, Street A: Early prediction of acute traumatic coagulopathy. Resuscitation 2011, 82:1208 1213.

19. Nunez TC, Voskresensky IV, Dossett L, Shinall R, Dutton WD, Cotton BA: Early prediction of massive transfusion in trauma: simple as $A B C$ (assessment of blood consumption)? J Trauma 2009, 66:346 352.

20. Ycel N, Lefering R, Maegele M, Vorweg M, Tjardes T, Ruchholtz S, Neugebauer EAM, Wappler F, Bouillon B, Rixen D, Polytrauma Study Group of the German Trauma Society: Trauma Associated Severe Hemorrhage (TASH)-Score: probability of mass transfusion as surrogate for life threatening hemorrhage after multiple trauma. J Trauma 2006, 60:1228 1237.

21. Vandromme MJ, Griffin RL, McGwin G Jr, Weinberg JA, Rue LW 3rd, Kerby JD: Prospective identification of patients at risk for massive transfusion: an imprecise endeavor. Am Surg 2011, 77:155 161. 
22. Schreiber M, Perkins J, Kiraly L, Underwood S, Wade CE, Holcomb JB: Early predictors of massive transfusion in combat casualties. J Am Coll Surg 2007, 205:541 545.

23. Rainer TH, Ho AMH, Yeung JHH, Cheung NK, Wong RSM, Tang N, Ng SK, Wong GKC, Lai PBS, Graham CA: Early risk stratification of patients with major trauma requiring massive blood transfusion. Resuscitation 2011 $82: 724729$

24. Brockamp T, Nienaber U, Mutschler M, Wafaisade A, Peiniger $S$, Lefering $R$, Bouillon B, Maegele M, TraumaRegister DGU: Predicting on-going hemorrhage and transfusion requirement after severe trauma: a validation of six scoring systems and algorithms on the TraumaRegister DGU. Crit Care 2012, 16:R129.

25. Cotton BA, Gunter OL, Isbell J, Au BK, Robertson AM, Morris JA Jr, St Jacques P, Young PP: Damage control hematology: the impact of a trauma exsanguinating protocol on survival and blood product utilization. J Trauma 2008, 64:1177 1183.

26. Inaba K, Branco BC, Rhee P, Blackbourne LH, Holcomb JB, Teixeira PG, Shulman I, Nelson J, Demetriades D: Impact of plasma transfusion in trauma patients who do not require massive transfusion. J Am Coll Surg 2010, 210:957 965.

27. Tonglet M, Minon JM, Damas F, Clanet M, Vergnion M: [Implementation of a massive transfusion protocol in an emergency department] [Article in French]. Rev Med Liege 2014, 69:82 88.

doi:10.1186/s13054-014-0648-0

Cite this article as: Tonglet et al:: Prehospital identification of trauma patients with early acute coagulopathy and massive bleeding: results of a prospective non-interventional clinical trial evaluating the Trauma Induced Coagulopathy Clinical Score (TICCS). Critical Care 2014 18:648.

\section{Submit your next manuscript to BioMed Central and take full advantage of:}

$\otimes$ Convenient online submission

$\otimes$ Thorough peer review

\No space constraints or color $\nabla$ gure charges

QImmediate publication on acceptance

$\otimes$ Inclusion in PubMed, CAS, Scopus and Google Scholar

$\otimes$ Research which is freely available for redistribution 